\title{
Cerebral Oximetry after Low Pressure versus Standard Pressure Pneumoperitoneum in Laparoscopic Nephrectomy
}

\author{
Cengiz Kaya ${ }^{1}$, Yasemin Burcu Ustun ${ }^{1}$, Sezgin Bilgin ${ }^{1}$, Ersin Koksal ${ }^{1}$, Ender Ozden ${ }^{2}$ and Burhan Dost ${ }^{1}$ \\ ${ }^{1}$ Department of Anesthesiology, Ondokuz Mayis University, School of Medicine, Kurupelit, Samsun, Turkey \\ ${ }^{2}$ Department of Urology, Ondokuz Mayis University, School of Medicine, Kurupelit, Samsun, Turkey
}

\begin{abstract}
Objective: To evaluate whether pneumoperitoneum pressure lower than the standard pressure would allow higher cerebral oxygen saturation $\left(\mathrm{rSO}_{2}\right)$ during laparoscopic nephrectomy (LN).

Study Design: Randomised controlled trial.

Place and Duration of Study: Ondokuz Mayis University Hospital, Samsun, Turkey, from January to November 2020.

Methodology: Sixty-two patients (aged 18-65 years; ASA I-III) scheduled for LN were equally divided into a low-pressure (LP; 8 $\mathrm{mmHg}$ ) and standard-pressure (SP; $14 \mathrm{mmHg}$ ) group. Mechanical ventilator settings were adjusted to maintain $32-37 \mathrm{mmHg}$ $\mathrm{ETCO}_{2}$ and $>96 \% \mathrm{SpO}_{2}$ throughout the surgery. The $\mathrm{rSO}_{2}$ was evaluated by near-infrared spectroscopy before and one minute after induction and then every five minutes until patient transfer to the recovery unit. Oxygen and carbon dioxide partial pressures, $\mathrm{pH}$, and haemoglobin, recorded at five minutes after induction, five and 30 minutes after insufflation, and 10 minutes after desufflation, were examined for correlations with $\mathrm{rSO}_{2}$.

Results: Both groups had similar $\mathrm{rSO}_{2}$, arterial blood gas, and haemoglobin values at all measurement times. The LP group showed no differences between the preoperative values and the values obtained at the different time points. In contrast, the SP group showed significant differences between the preoperative and the measured values (except at 25, 30, and 35 minutes) (p $=0.001$ ). Four patients $(12.9 \%)$ in both groups showed cerebral desaturation. The $\mathrm{rSO}_{2}$ values were moderately correlated with the $\mathrm{CO}_{2}$ and haemoglobin values.

Conclusion: Low insufflation pressure offered no advantages over standard pressure in terms of haemodynamics, arterial blood gases, cerebral oxygen saturation during $\mathrm{LN}$, and $\mathrm{CO}_{2}$ insufflation did not change $\mathrm{rSO}_{2}$ levels.
\end{abstract}

Key Words: Pneumoperitoneum, Spectroscopy, Oximetry, Nephrectomy, Surgery, Laparoscopic nephrectomy.

How to cite this article: Kaya C, Ustun YB, Bilgin S, Koksal E, Ozden E, Dost B. Cerebral Oximetry after Low Pressure versus Standard Pressure Pneumoperitoneum in Laparoscopic Nephrectomy. J Coll Physicians Surg Pak 2022; 32(03):346-351.

\section{INTRODUCTION}

Laparoscopy has become very popular in kidney surgery due to its association with better postoperative cardiorespiratory function, less postoperative pain, faster recovery, and early discharge. ${ }^{1}$ Nevertheless, laparoscopic nephrectomy (LN) can cause significant changes in cerebral physiology, in addition to cardiovascular and respiratory changes, due to the patient's position and the long duration of pneumoperitoneum. ${ }^{1,2}$

Correspondence to: Dr. Burhan Dost, Department of Anesthesiology, Ondokuz Mayis University, School of Medicine, Kurupelit, Samsun, Turkey

E-mail: burhandost@hotmail.com

Received: November 03, 2021; Revised: December 11, 2021; Accepted: December 29, 2021

DOI: https://doi.org/10.29271/jcpsp.2022.03.346
Decreases in respiratory system activity, lung compliance, volume, and capacity can lead to ventilation/perfusion mismatch and atelectasis. ${ }^{2}$ Increase in intra-abdominal pressure and indirect increase in intrathoracic pressure can lead to cardiovascular effects, such as decreased preload, stroke volume, and cardiac output. ${ }^{3}$ Increased intra-abdominal pressure and intrathoracic pressure also decreases cerebral venous drainage, increases intracranial pressure (ICP), and causescerebral blood flow or volume changes. Hypercapnia occurring with carbon dioxide absorption during pneumoperitoneum can further increase ICP by causing vasodilation of cerebral vessels. ${ }^{4,5}$

Patients undergoing major urological surgery are often of an advanced age with multiple comorbidities. They are, therefore, at risk for complications related to pneumoperitoneum and positioning. These physiological changes may negatively affect cerebral oxygen saturation $\left(\mathrm{rSO}_{2}\right) .^{5}$ Lower than standard pressures may allow avoidance of these effects.

Herein, we test the hypothesis that higher $\mathrm{rSO}_{2}$ levels can be 
attained with low pressure ( $\mathrm{LP}, 8 \mathrm{mmHg}$ ) pneumoperitoneum compared to standard pressure (SP, $14 \mathrm{mmHg}$ ) in patients undergoing LN.

\section{METHODOLOGY}

This study was approved by the Clinical Research Ethics Committee (Approval No. B.30.2.ODM.0.20.08/1725) and registered at Clinical Trials.gov (NCT04671121, December 16, 2020).

All participants provided written informed consent beforeenrollment. This prospective, double-blind study included 62 American Society of Anaesthesiologists (ASA) Physical Status class I-III patients aged 18-65 years, who underwent LN (simple, partial, or radical).

Patients with cerebrovascular diseases (cerebral ischaemia or haemorrhage), neurological disorders (epilepsy, dementia, Parkinson's and Alzheimer's diseases) uncontrolled diabetes or hypertension, advanced organ failure (functional class III-IV heart failure or stages 3-5 chronic kidney disease), baseline peripheral oxygen saturation $\left(\mathrm{SpO}_{2}\right)$ less than $96 \%$, or a haemoglobin $<9 \mathrm{gdL}-1$ were excluded.

Patients were randomly assigned into two groups: Group LP received LP $(n=31)$ and Group SP received SP pneumoperitoneum ( $n=31$ ). Randomisation was performed using a computer-generated random number list, using the closed envelope method. Each patient was asked to choose an envelope, and the patients were assigned to the study, according to the group written in the envelope. Patients and anaesthesiologists were blinded to the group assignments. The CONSORT flow diagram is shown in Figure 1.

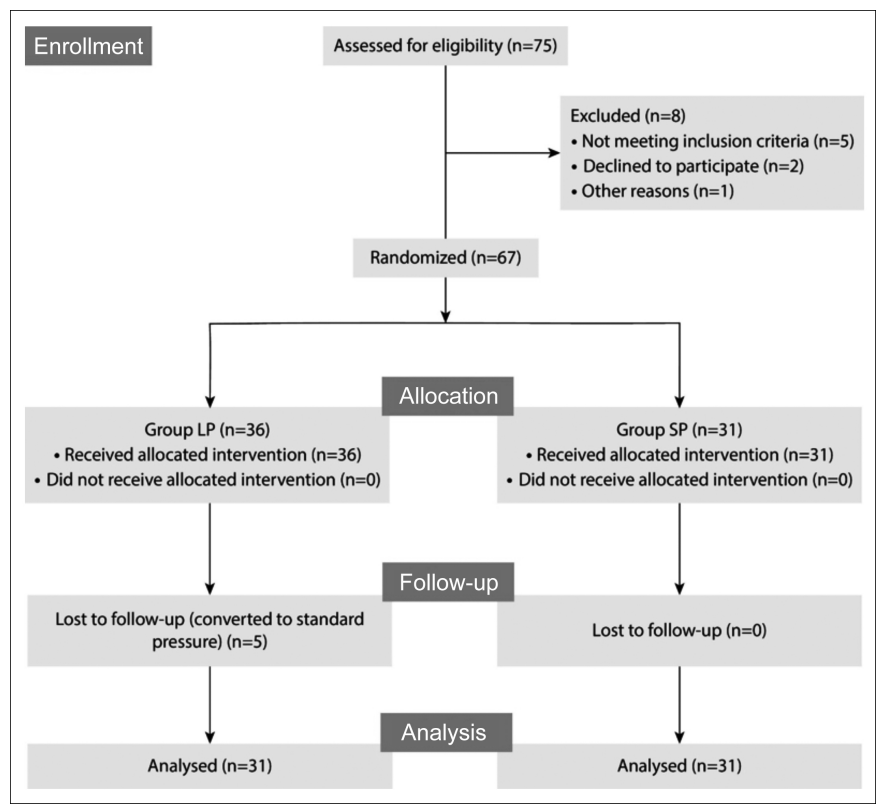

Figure 1: CONSORT flow diagram.

A standard anaesthesia protocol was used in both groups. Without premedication, patients were monitored with electrocardiogram, noninvasive blood pressure, peripheral oxygen saturation $\left(\mathrm{SpO}_{2}\right), \mathrm{rSO}_{2}$ (INVOS ${ }^{\mathrm{TM}} 5100 \mathrm{C}$ oximeter; Covidien, Mansfield, USA), and neuromuscular monitoring. Anaesthesia was induced with propofol, remifentanil, and rocuronium and maintained with $\mathrm{O}_{2} /$ Air, sevoflurane, and remifentanil IV infusion. A mechanical ventilator was used at standard settings. Pre-insufflation $\mathrm{SpO}_{2}$ values were maintained at $>96 \%$, while respiratory rate was determined with end-tidal $\mathrm{CO}_{2}\left(\mathrm{EtCO}_{2}\right)$ of $32-37 \mathrm{mmHg}$.

$\mathrm{CO}_{2}$ insufflation was performed in the patients who were placed in lateral semi-oblique $\left(60^{\circ}\right)$, and some flexion (jackknife) positions before the surgery were started. The mean arterial pressure (MAP), $\mathrm{HR}, \mathrm{SpO}_{2}$, and $\mathrm{ETCO}_{2}$ were recorded at preoperative, at one minute after induction, and then every five minutes until the patient went to the recovery unit. MAP and HR values were kept at $\pm 20 \%$ of preoperative values by changing the remifentanil infusion rate. Hypotension and bradycardia were treated with noradrenaline $4-8 \mu \mathrm{g}$, atropine $0.5 \mathrm{mg}$. Patients who required noradrenaline or atropine more than twice were excluded.

For the $\mathrm{rSO}_{2}$ measurements, before induction, the cerebral oximetry sensor was placed at least $2 \mathrm{~cm}$ above the eyebrows and $3 \mathrm{~cm}$ from the midline, in accordance with the manufacturer's instructions. Measurements were recorded at preoperative, at one minute after induction, and then every five minutes until the patient went to the recovery unit. Baseline values were accepted as the measurements obtained in the last 30 seconds of preoxygenation for three minutes with $80 \%$ oxygen before induction. Cerebral desaturation was defined as a decrease in the $\mathrm{SSO}_{2}$ of $>25 \%$ from the baseline value (if baseline value $<50$, reduction should be $>20 \%$ ), with this condition lasting $\geq 15$ seconds. In this case, patient's normotension was first achieved, and the patient's neck was checked, and external factors that could cause arterial or venous obstruction, if any, were corrected. If no improvement was noted despite these efforts, the inspired oxygen concentration was removed $100 \%$. The average of $\mathrm{rSO}_{2}$ values from the right and left sensors at each measurement time were used to evaluate cerebral oxygenation.

Oxygen and carbon dioxide partial pressures $\left(\mathrm{PaO}_{2}\right.$ and $\left.\mathrm{PaCO}_{2}\right)$, $\mathrm{pH}$, and haemoglobin values were measured at the 5 th minute (t1) after induction while the patient was in the supine position, at the 5th and 30th minutes after insufflation $(t 2, t 3)$, while the patient was in the lateral semi-oblique position, and at 10 minutes after desufflation, while the patient was in the supine position (t4).

Baseline demographics, preoperative haemoglobin, duration of anaesthesia and surgery, lateral position time, pneumoperitoneum time, recovery time, procedure types, and pathological diagnosis were recorded. Recovery time was defined as time from discontinuation of sevoflurane and remifentanil to extubation at the end of the surgical procedure. Any complications that developed were also recorded.

Typelerrorand the strength of the study were $5 \%$ and $80 \%$, respec- 
tively, with calculations performed with Minitab 16.0 software (Minitab Inc., State College, PA). The number of individuals for inclusion in each group was calculated as $\geq 28$ to show a standard deviation of 7.4 and a difference of $5.72 .{ }^{6}$ The sample size was increased by $10 \%$ to 31 patients per group to account for data losses. Data was analysed using SPSS (Version 22 for Windows, SPSS Inc., Chicago, IL, USA). Continuous variables were expressed as mean \pm standard deviation, and frequency data were expressed as number and percentage (\%). The Shapiro-Wilk test was used to evaluate thenormal distribution of the data. Between-group comparisons were made with Student's t-test for normally distributed variables and the Mann-Whitney U-test for data without normal distribution. The Friedman test was used for within-group comparisons and the Spearman correlation test for changes in the $\mathrm{rSO}_{2}$ values with time. The correlation coefficient ( $r$ ) values were assessed as showing a 'weak' relationship if $r=$ 0.00-0.24, 'moderate' if $r=0.25-0.49$, 'strong' if $r=0.50-0.74$ and 'very strong' if $r=0.75-1.00$. A value of $p<0.05$ was consideredstatistically significant.

Table I: Demographics and operative times.

\begin{tabular}{|c|c|c|c|}
\hline & $\begin{array}{l}\text { Group LP }(n=31) \\
\text { Mean } \pm S D \\
\text { or Median (IQR) }\end{array}$ & $\begin{array}{l}\text { Group SP }(n=31) \\
\text { Mean } \pm \text { SD } \\
\text { or Median (IQR) }\end{array}$ & P-value \\
\hline Age (year) & $55.2 \pm 9.9$ & $58.5 \pm 10.8$ & 0.224 \\
\hline BMI $\left(\mathrm{kg} \mathrm{m}^{-2}\right)$ & $27.1 \pm 5.1$ & $29.6 \pm 4.2$ & 0.139 \\
\hline Preoperative $\mathrm{Hb}\left(\mathrm{g} \mathrm{dL}^{-1}\right)$ & $13.4 \pm 2.0$ & $13.8 \pm 2.0$ & 0.462 \\
\hline ASA-PS Class & $2(1-2)$ & $2(2-2)$ & $0.193^{\dagger}$ \\
\hline Anaesthesia time (min) & $123.3 \pm 29.0$ & $137.4 \pm 42.6$ & 0.156 \\
\hline Surgical time (min) & $86(75-102.5)$ & $100(90-129)$ & $0.040^{\text {\# }}$ \\
\hline Pneumoperitoneum time (min) & $74.3 \pm 24.7$ & $91.3 \pm 37.6$ & 0.054 \\
\hline Lateral position time (min) & $87.5(73.7-100.0)$ & $98(77.5-130.0)$ & $0.171^{\dagger}$ \\
\hline Recovery time $(\mathrm{min})$ & $8(10-11)$ & $8.5(7-11.5)$ & $0.262^{\dagger}$ \\
\hline Gender (Male/Female) & $20(64.5) / 11(35.5)$ & $18(58.1) / 13(41.9)$ & 0.795 \\
\hline Comorbidities & & & \\
\hline Cardiovascular system related ${ }^{a}$ & $14(45.1)$ & 15 (48.37) & \\
\hline Endocrine system related ${ }^{\mathrm{b}}$ & $6(19.3)$ & $6(19.3)$ & 0.729 \\
\hline Respiratory system related ${ }^{c}$ & $2(6.4)$ & $4(12.9)$ & \\
\hline None & $9(2.9)$ & $6(19.4)$ & \\
\hline Nephrectomy & & & \\
\hline Partial & $17(54.8)$ & $15(48.3)$ & 0.966 \\
\hline Radical & $12(38.7)$ & $14(45.1)$ & \\
\hline Simple & $2(6.4)$ & $2(6.4)$ & \\
\hline ASA-PS class & & & \\
\hline & $13(41.9)$ & $6(19.4)$ & 0.116 \\
\hline II & $16(51.6)$ & $20(64.5)$ & \\
\hline & $2(6.5)$ & $5(16.1)$ & $<0.99$ \\
\hline Pathologic diagnosis & $28(90.3) / 3(9.7)$ & $28(90.3) / 3(9.7)$ & \\
\hline \multicolumn{4}{|c|}{$\begin{array}{l}\text { Data are presented as mean } \pm \text { standard deviation, median (IQR) or number (\%). BMI: Body mass index; } \\
\text { Hb: Haemoglobin concentration; ASA-PS: American Society of Anaesthesiologist Physical Status. } \\
{ }^{a} \text { Hypertension, coronary artery disease; }{ }^{b} \text { Type } 2 \text { diabetes, goiter; }{ }^{\circ} \text { Asthma. }{ }^{*} \text { Student's t-test was used for } \\
\text { the statistical analysis. }{ }^{\dagger} \text { Mann-Whitney U-test was used for the statistical analysis. }{ }^{\sharp} p<0.05 \text { statistically } \\
\text { significant versus group LP. }\end{array}$} \\
\hline
\end{tabular}

\section{RESULTS}

Demographic data, anaesthesia, lateral position, pneumoperitoneum and recovery time were similar for all patients. Surgical durations were shorter in the LP group compared to SP group (median [IQR], 86 [75-102.5] and 100 [90-129], $p=0.040$, respectively, Table I). The HR was higher in the LP group than in the SP group at 30 and 35 minutes $(p=0.019$ and $p=0.018$, respectively). The mean arterial pressure (MAP) was higher preoperatively in the LP group $(p=0.001)$ but higher in the SP group at 80 and $115 \mathrm{~min}(p=0.019$ and $p=0.012$, respectively). The $\mathrm{SpO}_{2}$ and $\mathrm{EtCO}_{2}$ values were similar in both groups.

There was no marked difference in the $\mathrm{rSO}_{2}$ (1423 measurements), arterial blood gas (ABG), and haemoglobin values in both groups at all measurement times (Figure 2, Table II). Within-group comparisons showed no differences between the preoperative values and other measurement times in the LP group ( $p=0.939$ ); however, significant differences were evident (except at 25, 30, and 35 minutes) in the SP group ( $p=$ $0.001)$. Cerebral desaturation occurred in four patients ( $12.9 \%)$ in both groups, but only during the insufflation period. All patients were treated by applying $100 \%$ oxygen.

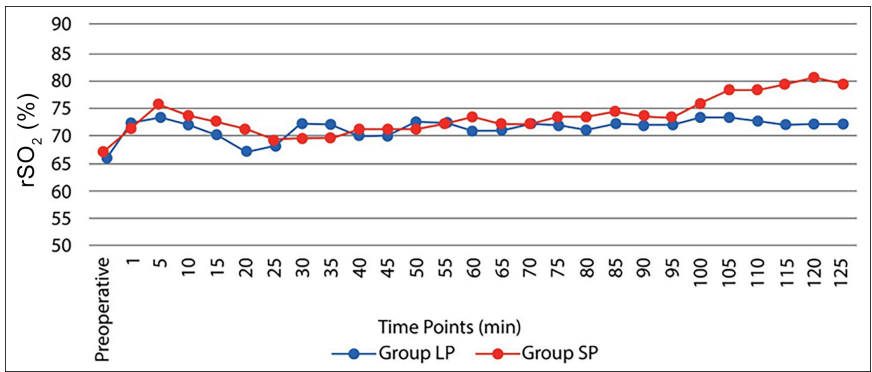

Figure 2: $\mathrm{rSO}_{2}(\%)$ values of the groups. $\mathrm{rSO}_{2}$, regional cerebral oxygen saturation.

Table Il: Arterial blood gas and haemoglobin values of the groups.

\begin{tabular}{|c|c|c|c|c|}
\hline & & $\begin{array}{l}\text { Group LP }(n=31) \\
\text { Mean } \pm \text { SD }\end{array}$ & $\begin{array}{l}\text { Group SP }(n=31) \\
\text { Mean } \pm \text { SD }\end{array}$ & P-value \\
\hline & $\mathrm{pH}$ & $7.4 \pm 0.04$ & $7.4 \pm 0.05$ & 0.94 \\
\hline \multirow[t]{4}{*}{$t_{1}$} & $\mathrm{PaO}_{2}(\mathrm{mmHg})$ & $288.7 \pm 91.3$ & $305.0 \pm 78.3$ & 0.47 \\
\hline & $\mathrm{PaCO}_{2}(\mathrm{mmHg})$ & $34.1 \pm 3.9$ & $33.3 \pm 4.6$ & 0.46 \\
\hline & $\mathrm{Hb}(\mathrm{g} / \mathrm{dL})$ & $12.2 \pm 1.7$ & $12.3 \pm 2.1$ & 0.84 \\
\hline & $\mathrm{pH}$ & $7.4 \pm 0.05$ & $7.3 \pm 0.05$ & 0.30 \\
\hline \multirow[t]{4}{*}{$t_{2}$} & $\mathrm{PaO}_{2}(\mathrm{mmHg})$ & $201.7 \pm 58.6$ & $180.3 \pm 65.0$ & 0.19 \\
\hline & $\mathrm{PaCO}_{2}(\mathrm{mmHg})$ & $35.2 \pm 5.3$ & $35.8 \pm 4.1$ & 0.64 \\
\hline & $\mathrm{Hb}(\mathrm{g} / \mathrm{dL})$ & $11.0 \pm 1.9$ & $12.1 \pm 1.7$ & 0.12 \\
\hline & $\mathrm{pH}$ & & $7.3 \pm 0.06$ & 0.19 \\
\hline \multirow[t]{2}{*}{$t_{3}$} & $\mathrm{PaO}_{2}(\mathrm{mmHg})$ & $194.6 \pm 76.4$ & $168.2 \pm 54.7$ & 0.17 \\
\hline & $\mathrm{PaCO}_{2}(\mathrm{mmHg})$ & $37.6 \pm 5.1$ & $36.8 \pm 3.8$ & 0.55 \\
\hline $\mathbf{t}_{4}$ & $\begin{array}{l}\mathrm{Hb}(\mathrm{g} / \mathrm{dL}) \\
\mathrm{pH} \\
\mathrm{PaO} 2(\mathrm{mmHg}) \\
\mathrm{PaCO} 2(\mathrm{mmHg}) \\
\mathrm{Hb}(\mathrm{g} / \mathrm{dL})\end{array}$ & $\begin{array}{l}10.7 \pm 2.0 \\
7.3 \pm 0.05 \\
199.2 \pm 79.7 \\
37.3 \pm 3.8 \\
10.8 \pm 1.9 \\
\end{array}$ & $\begin{array}{l}11.6 \pm 2.6 \\
7.3 \pm 0.07 \\
179.7 \pm 63.8 \\
39.4 \pm 5.5 \\
12.1 \pm 1.7\end{array}$ & $\begin{array}{l}0.38 \\
0.15 \\
0.37 \\
0.14 \\
0.11 \\
\end{array}$ \\
\hline \multicolumn{5}{|c|}{$\begin{array}{l}\text { Data are presented as mean } \pm \text { standard deviation. } \mathrm{PaO}_{2}: \text { Partial pressure of arterial } \\
\text { oxygen; } \mathrm{PaCO}_{2}: \text { Partial pressure of arterial carbon dioxide; } \mathrm{Hb} \text { : Haemoglobin } \\
\text { concentration. }{ }^{*} \text { Student's } t \text {-test was used for the statistical analysis. } t_{1}: 5 \text { th minute } \\
\text { post-induction with the patient in the supine position, } t_{2}: 5 \text { th minute post- } \\
\text { insufflation with the patient in the flank semi-oblique position, } t_{3}: 30 \text { th minute post- } \\
\text { insufflation with the patient in the flank semi-oblique position, } t_{4}: 10 \text { th minute after } \\
\text { desufflation with the patient in the supine position. }\end{array}$} \\
\hline
\end{tabular}

A moderate positive correlation was detected between $\mathrm{rSO}_{2}$ and $\mathrm{CO}_{2}$ and haemoglobin in $\mathrm{t} 1(\mathrm{p}=0.001$ and $\mathrm{p}=0.002)$, a strong positive correlation between $\mathrm{rSO}_{2}$ and haemoglobin in $\mathrm{t} 2$ $(\mathrm{p}=0.005)$, a moderate positive correlation between $\mathrm{rSO}_{2}$ and $\mathrm{CO}_{2}$ in $\mathrm{t} 3(\mathrm{p}=0.003)$, and a strong positive correlation between $\mathrm{rSO}_{2}$ and $\mathrm{CO}_{2}$ int $4(\mathrm{p}=0.001)$. Only a moderate negative correlation was found with $\mathrm{pH}(\mathrm{p}=0.024$, Table III).

\section{DISCUSSION}

In this study, haemodynamics variables, ABG, haemoglobin and $\mathrm{rSO}_{2}$ values of the LP and SP groups were similar. Following an increase in $\mathrm{rSO}_{2}$ after induction in both groups, a slight downward trend was observed followed by constant course throughout. These changes were statistically significant in the SP group. Additionally, $\mathrm{CO}_{2}$ and haemoglobin was found to have a moderate to strong positive correlation with $\mathrm{rSO}_{2}$. 
Table III: Relationship between $\mathrm{rSO}_{2}$, arterial blood gas and haemoglobin values at $t_{1}, t_{2}, t_{3}$ and $t_{4}$.

\begin{tabular}{|c|c|c|c|c|c|c|c|c|}
\hline \multirow{2}{*}{$\mathrm{rSO}_{2}$} & \multicolumn{2}{|c|}{$t_{1}$} & \multicolumn{2}{|c|}{$t_{2}$} & \multicolumn{2}{|c|}{$t_{3}$} & \multicolumn{2}{|c|}{$t_{4}$} \\
\hline & $r$ & P-value & $r$ & P-value & $r$ & P-value & $r$ & P-value \\
\hline $\mathrm{pH}$ & -0.137 & 0.314 & -0.137 & 0.300 & -0.124 & 0.397 & -0.353 & $0.024^{*}$ \\
\hline $\mathrm{PaO}_{2}(\mathrm{mmHg})$ & -0.179 & 0.187 & 0.052 & 0.694 & -0.083 & 0.573 & -0.167 & 0.298 \\
\hline $\mathrm{PaCO}_{2}(\mathrm{mmHg})$ & 0.446 & $0.001 *$ & 0.071 & 0.595 & 0.417 & $0.003^{*}$ & 0.507 & $0.001 *$ \\
\hline $\mathrm{Hb}\left(\mathrm{g} \mathrm{dL}^{-1}\right)$ & 0.487 & $0.002 *$ & 0.528 & $0.005 *$ & 0.176 & 0.399 & 0.438 & 0.053 \\
\hline
\end{tabular}

In the present study, cerebral oxygenation, hypoxia, physiological variables, and arterial blood gas values were similar in both groups. Previous studies evaluating the relationship between pneumoperitoneum and cerebral oxygenation have provided contradictory data: Inal et al. considered two different pneumoperitoneum pressures (10 vs. $14 \mathrm{mmHg}$ ) in laparoscopic cholecystectomy cases and reported higher $\mathrm{rSO}_{2}$ values in the LP group; ${ }^{6}$ whereas, LP did not affect the $\mathrm{rSO}_{2}$ in this study. This may be due to greater frequency of $\mathrm{rSO}_{2}$ data collection (5 vs. 15 minutes) and longer anaesthesia duration ( 130 vs. 48 minutes) that allowed us to capture more changes in $\mathrm{rSO}_{2}$. The reverse Trendelenburg position applied in cholecystectomy may also have exacerbated the cerebral effects of the pneumoperitoneum by reducing the cerebral blood volume. ${ }^{7}$

De Waal et al. showed increases in $\mathrm{ETCO}_{2}$, cerebral blood volume, and $\mathrm{rSO}_{2}$ after insufflation in children undergoing LP (5-8 $\mathrm{mmHg}$ ) pneumoperitoneum during laparoscopic fundoplication, ${ }^{8}$ as well as significant cerebral vasodilation with $\mathrm{PaCO}_{2}$ and increased cerebral blood flow-volume. Conversely, the $\mathrm{rSO}_{2}$ values in the LP group were similar to preoperative values. However, de Waal et al. determined baseline $\mathrm{rSO}_{2}$ values after providing moderate hypocapnia and before insufflation and detected a $\sim 25 \%$ increase in $\mathrm{PaCO}_{2}$ throughout the pneumoperitoneum.

However, $\mathrm{ETCO}_{2}$ and $\mathrm{PaCO}_{2}$ values were similar in both our groups and may have prevented any $\mathrm{rSO}_{2}$ changes caused by $\mathrm{CO}_{2}$-induced cerebral vasodilation.

A comparison of laparoscopic (8-10 $\mathrm{mmHg}$ ) and open pediatric appendectomy revealed no effect of pneumoperitoneum on $\mathrm{rSO}_{2}$ values, ${ }^{9}$ suggesting intact venous return and protection of cardiovascular stability when intraabdominal pressure $<15 \mathrm{mmHg}$. Öztan et al. determined that pneumoperitoneum had no effect on haemodynamics, and their $\mathrm{rSO}_{2}$ values were similar to those of the LP group. ${ }^{10}$ Both these studies examined only ASA I patients, whereas $58.1 \%$ of our patients were ASA II-III; nevertheless, the $\mathrm{rSO}_{2}$ values in these patients were similarly unaffected by pneumoperitoneum pressure.

Lee et al. reported a significant decrease in $\mathrm{rSO}_{2}$ during laparoscopic (12-15 $\mathrm{mmHg}$ ) gynecological surgery in a $15^{\circ}$ Trendelenburg position and no increase due to pneumoperi- toneum unless hypercapnia occurred. ${ }^{11}$ The Trendelenburg position was proposed to increase ICP and decrease carotid artery blood flow, cerebral perfusion pressure, and $\mathrm{rSO}_{2}$ values; whereas, pneumoperitoneum did not cause any change in cerebral blood flow and ICP as long as normocarbia was achieved. However, Park et al. found increased $\mathrm{rSO}_{2}$ values in patients placed in the $30^{\circ}$ Trendelenburg position during robotic surgery and associated this with the prevention of cerebral venous drainage by the Trendelenburg position, decreased venous drainage from the lumbar plexus with increased intraabdominal pressure with pneumoperitoneum, and increased cerebral blood volume and ICP due to increased $\mathrm{PaCO}_{2}{ }^{12}$ Li et al. observed that $\mathrm{rSO}_{2}$ increased with steep Trendelenburg position, and associated this with increased cerebral blood flow. ${ }^{13}$ Conversely, Beck et al., in their study comparing robotic and open radical prostatectomy, found that steep Trendelenburg position and pneumoperitoneum did not impair cerebral autoregulation. ${ }^{14}$

In this study, where normocapnia was provided in all patients, it was found an increase in the SP group compared to the preoperative values. Park et al. suggested that a single mechanism seems unlikely to account for the increase of cerebral blood volume and ICP. Studies have shown a negative correlation between $\mathrm{rSO}_{2}$ and ICP; ${ }^{11,15}$ however, the increased cerebral oxyhaemoglobin with increased cerebral blood volume and reduction in haemoglobin and total haemoglobin may be responsible for increased $\mathrm{rSO}_{2}$ values. ${ }^{16}$ Moreover, the lateral position and slight flexion applied to these patients should not have affected cerebral haemodynamics to the extent of steep Trendelenburg position. The increase we detected in $\mathrm{rSO}_{2}$ values was similar to that reported previously. ${ }^{9,11}$

Cerebral desaturation rates of $\sim 8.5 \%$ have been reported in patients during different laparoscopic surgeries. ${ }^{5,11}$ Cerebral desaturation was observed in more of our patients $(\sim 13 \%)$ than reported in previous studies. Tuna et al. found a much lower rate (5\%); however, their data may reflect their inclusion of only ASA I patients; they also did not report the surgical position used. ${ }^{9}$ Casati et al. found a cerebral desaturation rate of $20 \%$ in elderly abdominal surgery patients, ${ }^{17}$ suggesting that older age (73 \pm 5 years) and longer surgical duration (259 \pm 94 minutes) could increase this rate.

One animal study reported positive correlation between 
intra-abdominal pressure and ICP. ${ }^{18}$ In human patients with normal ICP, this increase has no detrimental effect, but it may worsen in patients with increased ICP (due to cerebral ischaemia, intracerebral lesion, or shunt). ${ }^{19}$ However, increases in cerebral blood flow, which contributes to increases in ICP, is associated more with hypercapnia than with pneumoperitoneum and is absent under normocapnia. ${ }^{20}$ The effects of pneumoperitoneum on cardiac output and cerebral oxygen saturation in children can also be minimised by optimising haemodynamic parameters. ${ }^{21}$ In the present study, close haemodynamic monitoring and normocapnia prevented adverse effects of pneumoperitoneum pressure on cerebral oxygenation.

As mentioned earlier, pneumoperitoneum causes cardiorespiratory changes. However, literature shows that decreased lung compliance at standard versus LP does not affect $\mathrm{ETCO}_{2}, \mathrm{SpO}_{2}$, or arterial blood gases, in agreement with this study. ${ }^{22-24}$ Cho et al. found no difference between static (HR and MAP) and dynamic cardiac parameters (cardiac and stroke volume index) in LP and SP groups undergoing laparoscopic colorectal surgery. ${ }^{25}$ Similarly, a comparison of low and standard pressure in terms of cardiac functions reveals no difference between HR and MAP. ${ }^{6}$

This study has some limitations. Although most of our patients tolerated pneumoperitoneum without serious changes in $\mathrm{rSO}_{2}$ values, cerebral desaturation occurred in some, and the potential effects of $\mathrm{rSO}_{2}$ decreases on postoperative neurocognitive functions are unknown. The depth of anaesthesia may not have been constant, as volatile anaesthetic concentrations were not adjusted to the bispectral index value, so this may have affected $\mathrm{rSO}_{2}$ values by disrupting the harmony between the cerebral blood flow and metabolic oxygen rate. ASA IV patients were also not included, where changes in $\mathrm{rSO}_{2}$ could be more pronounced due to possible cardiorespiratory/cerebrovascular diseases.

\section{CONCLUSION}

There was no advantage of LP in terms of haemodynamic variables, arterial blood gases, and cerebral oxygen saturation. Most patients tolerate $\mathrm{CO}_{2}$ insufflation without any significant $\mathrm{rSO}_{2}$ changes; however, further studies should include patients with comorbid conditions affecting cerebral oxygenation and should evaluate postoperative cognitive functions.

\section{ETHICAL APPROVAL:}

The study was approved by the Institutional Ethics Committee of University of Ondokuz Mayis University. (Date: 16.12.2020, Approval No. B.30.2.0DM.0.20.08/1725).

\section{PATIENTS' CONSENT:}

Informed consents were obtained from all patients/relatives before the study began.

\section{CONFLICT OF INTEREST:}

The authors declared no conflict of interest.

\section{AUTHORS' CONTRIBUTION:}

CK, EK: Conceptualisation, methodology, software.

YBU, CK: Data curation, writing, original draft preparation.

BD, SB: Data curation, visualisation, investigation.

EO: Supervision.

$B D, E K$ : Software, validation.

CK, BD, SB, YBU, EK, EO: Writing, reviewing and editing.

\section{REFERENCES}

1. Nasrallah G, Souki FG. Perianesthetic management of laparoscopic kidney surgery. Curr Urol Rep 2018; 19(1):1. doi:10.1007/s11934-018-0757-4.

2. Fahy BG, Barnas GM, Flowers JL, Jacobs SC, Plotkin JS, Delaney PA. Effects of split torso positioning and laparoscopic surgery for donor nephrectomy on respiratory mechanics. J Clin Anesth 1998; 10(2):103-8. doi:10. 1016/s0952-8180(97)00251-Todd E, Vasdev N, Soomro NA. Physiologic and anesthetic considerations in octogenarians undergoing laparoscopic partial nephrectomy. Rev Urol 2013; 15(1):23-31.

3. Ozdemir-van Brunschot DM, van Laarhoven KC, Scheffer GJ, Pouwels S, Wever KE, Warle MC. What is the evidence for the use of low-pressure pneumoperitoneum? A systematic review. Surg Endosc 2016; 30(5):2049-65. doi:10.1007/ s00464-015-4454-9.

4. Gipson $\mathrm{CL}$, Johnson GA, Fisher R, Stewart A, Giles G, Johnson $\mathrm{JO}$, et al. Changes in cerebral oximetry during peritoneal insufflation for laparoscopic procedures. J Minim Access Surg 2006; 2(2):67-72. doi:10.4103/0972-9941.26651.

5. Inal MT, Memis D, Sezer A, Turan N. The effects of different insufflation pressures on cerebral oxygen saturation in patients undergoing laparoscopic cholecystectomy. Indian J Surg 2020; 82(3):377-81. doi:10.1007/s12262-019-01973-6.

6. Kitajima T, Okuda Y, Yamaguchi S, Takanishi T, Kumagai M, Ido K. Response of cerebral oxygen metabolism in the headup position during laparoscopic cholecystectomy. Surg Laparosc Endosc 1998; 8(6):449-52.

7. de Waal EE, de Vries JW, Kruitwagen CL, Kalkman CJ. The effects of low-pressure carbon dioxide pneumoperitoneum on cerebral oxygenation and cerebral blood volume in children. Anesth Analg 2002; 94(3):500-5. doi:10.1097/0000 0539-200203000-00005.

8. Tuna AT, Akkoyun I, Darcin S, Palabiyik O. Effects of carbon dioxide insufflation on regional cerebral oxygenation during laparoscopic surgery in children: A prospective study. Braz J Anesthesiol 2016; 66(3):249-53. doi:10.1016/j.bjane.2014. 10.004.

9. Oztan MO, Aydin G, Cigsar EB, Sutas Bozkurt P, Koyluoglu G. Effects of carbon dioxide insufflation and trendelenburg position on brain oxygenation during laparoscopy in children. Surg Laparosc Endosc Percutan Tech 2019; 29(2):90-4. doi:10.1097/SLE.0000000000000593.

10. Lee JR, Lee PB, Do SH, Jeon YT, Lee JM, Hwang JY, et al. The effect of gynaecological laparoscopic surgery on cerebral oxygenation. J Int Med Res 2006; 34(5):531-6. doi:10.1177/ 


\section{1.}

11. Park EY, Koo BN, Min KT, Nam SH. The effect of pneumoperitoneum in the steep Trendelenburg position on cerebral oxygenation. Acta Anaesthesiol Scand 2009; 53(7):895-9. doi:10.1111/j.1399-6576.2009.01991.x.

12. Li Y, Huang D, Su D, Chen J, Yang L. Postoperative cognitive dysfunction after robot-assisted radical cystectomy (RARC) with cerebral oxygen monitoring an observational prospective cohort pilot study. BMC Anesthesiol 2019; 19(1):202. doi:10.1186/s12871-019-0877-5.

13. Beck S, Ragab H, Hoop D, Meßner-Schmitt A, Rademacher $\mathrm{C}$, Kahl U, et al. Comparing the effect of positioning on cerebral autoregulation during radical prostatectomy: A prospective observational study. J Clin Monitoring Computing 2021; 35(4):891-901. doi:10.1007/s10877-020-00549-0.

14. Dunham CM, Sosnowski C, Porter JM, Siegal J, Kohli C. Correlation of noninvasive cerebral oximetry with cerebral perfusion in the severe head injured patient: A pilot study. J Trauma 2002; 52(1):40-6. doi:10.1097/00005373-200201000-00009.

15. Kitajima $T$, Shinohara M, Ogata H. Cerebral oxygen metabolism measured by near-infrared laser spectroscopy during laparoscopic cholecystectomy with $\mathrm{CO}_{2}$ insufflation. Surg Laparosc Endosc 1996; 6(3):210-2.

16. Casati A, Fanelli G, Pietropaoli P, Proietti R, Tufano R, Danelli $\mathrm{G}$, et al. Continuous monitoring of cerebral oxygen saturation in elderly patients undergoing major abdominal surgery minimizes brain exposure to potential hypoxia. Anesth Analg 2005; 101(3):740-7. doi:10.1213/01.ane.00001 66974.96219.cd.

17. Josephs LG, Este-McDonald JR, Birkett DH, Hirsch EF. Diagnostic laparoscopy increases intracranial pressure. J Trauma 1994; 36(6):815-8; discussion 8-9. doi:10.1097/00005373-
199406000-00011.

18. Uzzo RG, Bilsky M, Mininberg DT, Poppas DP. Laparoscopic surgery in children with ventriculoperitoneal shunts: Effect of pneumoperitoneum on intracranial pressure--preliminary experience. Urology 1997; 49(5):753-7. doi:10.1016/S0090-4295(97)00233-1.

19. Moncure M, Salem R, Moncure K, Testaiuti M, Marburger R, Ye $X$, et al. Central nervous system metabolic and physiologic effects of laparoscopy. Am Surg 1999; 65(2):168-72.

20. Maesani M, Pares F, Michelet D, Abdat R, Hilly J, Diallo T, et al. Haemodynamic and cerebral oxygenation during paediatric laparoscopy in fluid optimised patients. $\mathrm{Br} J$ Anaesth 2016; 116(4):564-6. doi:10.1093/bja/aew041.

21. Sefr R, Puszkailer K, Jagos F. Randomised trial of different intraabdominal pressures and acid-base balance alterations during laparoscopic cholecystectomy. Surg Endosc 2003; 17(6):947-50. doi:10.1007/s00464-002-9046-9.

22. Park JS, Ahn EJ, Ko DD, Kang H, Shin HY, Baek $\mathrm{CH}$, et al. Effects of pneumoperitoneal pressure and position changes on respiratory mechanics during laparoscopic colectomy. Korean J Anesthesiol 2012; 63(5):419-24. doi:10.4097/kjae.2012.63.5.419.

23. Vijayaraghavan N, Sistla SC, Kundra P, Ananthanarayan PH, Karthikeyan VS, Ali SM, et al. Comparison of standard-pressure and low-pressure pneumoperitoneum in laparoscopic cholecystectomy: A double blinded randomised controlled study. Surg Laparosc Endosc Percutan Tech 2014; 24(2):127-33. doi:10.1097/SLE.0b013e3182937980.

24. Cho YJ, Paik H, Jeong SY, Park JW, Jo WY, Jeon Y, et al. Lower intra-abdominal pressure has no cardiopulmonary benefits during laparoscopic colorectal surgery: A double-blind, randomised controlled trial. Surg Endosc 2018; 32(11):4533-42. doi:10.1007/s00464-018-6204-2. 